\title{
FESTIVAL DO TEMPLO DÔ (LẼ̃ HộI ĐỀN ĐÔ)
}

\author{
Carlos Eduardo Bione Sidrônio de Lima ${ }^{l}$
}

Resumo: Este ensaio fotográfico busca apresentar, a partir de um conjunto de imagens feitas in loco, alguns aspectos históricos e culturais ligados à prática do culto aos imperadores vietnamitas da Dinástica Lý. Este trabalho se enquadra na grande área dos estudos historiográficos sobre Ásia, abordando, mais especificamente, o Sudeste Asiático. Tendo em vista que muito do imaginário ocidental acerca do Vietnam ainda está relacionado ao legado do conflito bélico que se estendeu por longos vinte anos (1955-1975), pretendemos com este ensaio (i) contribuir para a difusão de uma abordagem menos belicocentrada sobre a região e (ii) promover outras possibilidades de narrativas sobre a história do Vietnam.

Palavras-chave: História da Ásia; Sudeste Asiático; Vietnam; Dinastia Lý; culto imperial.

Todos os anos, durante 4 dias, do $14^{\circ}$ ao $17^{\circ}$ dia do $3^{\circ}$ mês do calendário lunar, tem lugar na vila de Đình Bảng, distrito de Từ Sơn, província de Bắc Ninh, a cerca de 40 minutos da capital do país, Hanói, o Festival do Templo Dô - Lễ hội đền Đô, em língua vietnamita. Trata-se de um grande feriado festivo que mobiliza toda a região para celebrar a coroação do primeiro dos oito monarcas que compõem o período da Dinastia Lý (1009-1225): o imperador Lý Thái Tổ.

No final do primeiro milênio de nossa era, recém-saído do jugo do império sínico dos Han do Sul, o Đại Cồ Việt - antigo nome do país,

${ }^{1}$ Graduando no $6^{\circ}$ período do curso de História da Universidade de Brasília (UnB). Orientador Prof. Dr. Luiz César de Sá (Teoria da História e História da Historiografia). Email para contato: cadubione@gmail.com. 
Cadernos de Clio, Curitiba, v. 11, nº. 2, 2020

"Grande Vietnam" - encontrava-se mergulhado em conflitos administrativos provinciais e intensas disputas relacionadas à sucessão ao trono. Morto em circunstâncias suspeitas, o último imperador dos Lê, Lê Long Đĩnh, deixara como herdeiro um filho de dez anos e um país à beira do colapso. Uma junta mandarinal interveio na sucessão e nomeou o então aspirante a mandarim Lý Công Uẩn - entronizado, em 1009, com o nome Lý Thái Tổ. Fundava-se então a Dinastia Lý, que conseguiu reconduzir o país a um longo período de estabilidade.

O Templo Dô teve seu primeiro pavilhão erguido em 1028, na vila natal de Lý Thái Tổ, a pedido de seu filho e sucessor, Lý Thái Tông, para abrigar os restos mortais do pai. Anteriormente, todos os outros titulares da dinastia também foram ali sepultados.

O festival reúne atividades de culto, mas também de lazer. É um momento festivo de reunião familiar, da parentagem mais ampla e da comuna. No $2^{\circ}$ dia, o mais importante, os aldeões acompanham o longo cortejo, pelas ruas, do palanquim imperial seguido por dragões, mandarins, artesãos, estudantes e outras fileiras representando diferentes grupos sociais. O cortejo segue em marcha solene até o Templo Dô. À entrada, uma longa pausa para que seja encenado um combate simbólico entre dois dragões. Vitorioso aquele que representa a Casa dos Lý, a marcha segue enfim para o interior do templo onde acontece o culto, com vasta queima de incenso, oferenda de frutas e objetos votivos. Em meio à neblina formada pela fumaça - elo entre os viventes e o além - têm lugar igualmente os festejos mundanos. 
Apesar de ser, pelo menos desde 1976, um país sem religião oficial, o culto aos ancestrais é uma prática historicamente difundida no Vietnam. Trata-se de um desdobramento do preceito da piedade filial, um dos pilares do confucionismo implantado durante a milenar ocupação chinesa. Decerto que o culto aos imperadores Lý distingue-se dessa prática familiar, porém dela se aproxima em sentido de vigília, respeito e agradecimento aos ancestrais pela boa condução do país e pelos esforços de manterem sua integridade como império livre do jugo das iminentes ameaças de invasão.

As fotografias que o leitor verá nas páginas seguintes integram um conjunto maior de imagens feito na edição 2009 do festival. Tivemos a oportunidade de acompanhar os festejos graças ao convite de uma aluna nossa, da Universidade de Hanói, natural da província de Bắc Ninh. Para que o ensaio apresentado adquirisse organicidade, as imagens selecionadas representam momentos do grande cortejo, com membros representantes da corte dos Lý, até a entrada do templo. Esse é considerado o ponto mais importante de todo o festival.

Nossa preocupação principal, antes de chegarmos ao evento, era a de participar da forma mais próxima possível das ações desempenhadas pelos participantes locais. Sem deixar, assim, que a imagem "daquele que olha de fora" de alguma forma produzisse algum incômodo nas dinâmicas. Como única presença ocidental, em meio à multidão que seguia o cortejo, ser-nos-ia difícil alcançar um apagamento completo da imagem estrangeira - este era tampouco nosso objetivo. 
Nesse sentido, nossa participação tentou se aproximar ao máximo do papel desempenhado por todos ali, o da interação colaborativa ao longo de todo o cortejo, acompanhando cada momento de dramaticidade do jogo encenado. Os atores que encarnam os antigos imperadores; os bonequeiros que dão vida aos dragões; os moradores que entram no jogo de cena representando os membros da corte e, sobretudo, o público que acompanha atento, mobilizado, cada momento do longo desfile e da batalha final entre os dragões até que todos, finalmente, possam adentrar o espaço do templo e celebrar a memória do imperador Lý Thái Tổ. Assim, buscamos construir uma espécie de etnografia imagética daquele momento.

O ensaio é apresentado em dois enfoques distintos, o primeiro com imagens em preto e branco, o segundo, coloridas. Essa escolha foi feita com vistas a pôr em evidência duas abordagens específicas em relação ao festejo. O primeiro conjunto, de imagens em preto e branco, ao "apagar" intencionalmente o lusco-fusco da explosão de cores do festival, busca direcionar a atenção do olhar observador para a dramaticidade das diferentes etapas no avançar do cortejo. Ao observador mais atento, chamamos a atenção para o jogo de perspectivas, observador/observado, construído nas seis primeiras fotografias. Nelas permanece, em silêncio de olhares curiosos, a linha tênue de uma alteridade: quem observa e quem é observado?

No segundo conjunto, as cores irrompem mostrando a euforia dos instantes finais do cortejo à entrada do templo. Em seguida, dentro do templo, têm lugar as cerimônias de oferenda de objetos votivos e a queima 
de incensos. Ali, o amarelo ouro e o vermelho escarlate transbordam os limites das cenas. São as cores predominantes em toda a heráldica vietnamita - para a casa dinástica dos Lý especialmente, o amarelo tem forte simbologia. $\mathrm{O}$ verde fulgurante, onipresente no cenário natural, é complementado pelo oliva opaco de peças indumentárias do antigo exército nacional, que, em réplicas de casquettes việt-cong, marcam presença entre os devotos.

Distante de todo e qualquer orientalismo voyeur, não é o anacronismo de um exotismo cênico que nos interessa aqui - tampouco a imposição de uma leitura interpretativa cartesiana que busque identificar possíveis "contradições" no ecletismo ritualístico do festival. Esperamos, tão somente, que o ensaio fotográfico que se segue apresente-se ao olhar do observador como uma porta aberta para um importante instante festivo da cultura vietnamita, um convite à atenção, um caminho possível de (re)aproximações e de entendimentos. 
Cadernos de Clio, Curitiba, v. 11, nº. 2, 2020
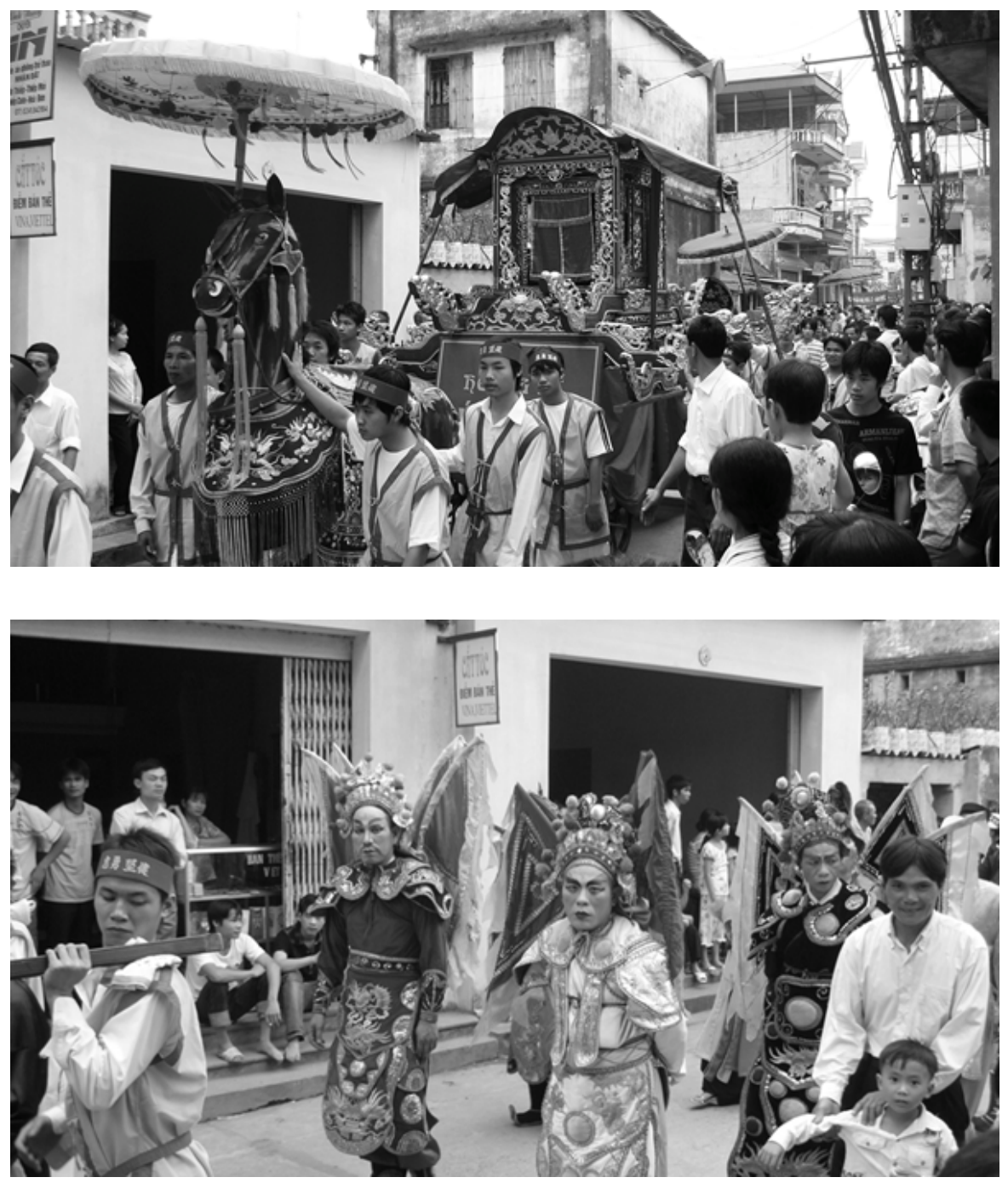
Cadernos de Clio, Curitiba, v. 11, $\mathrm{n}^{\circ} .2,2020$
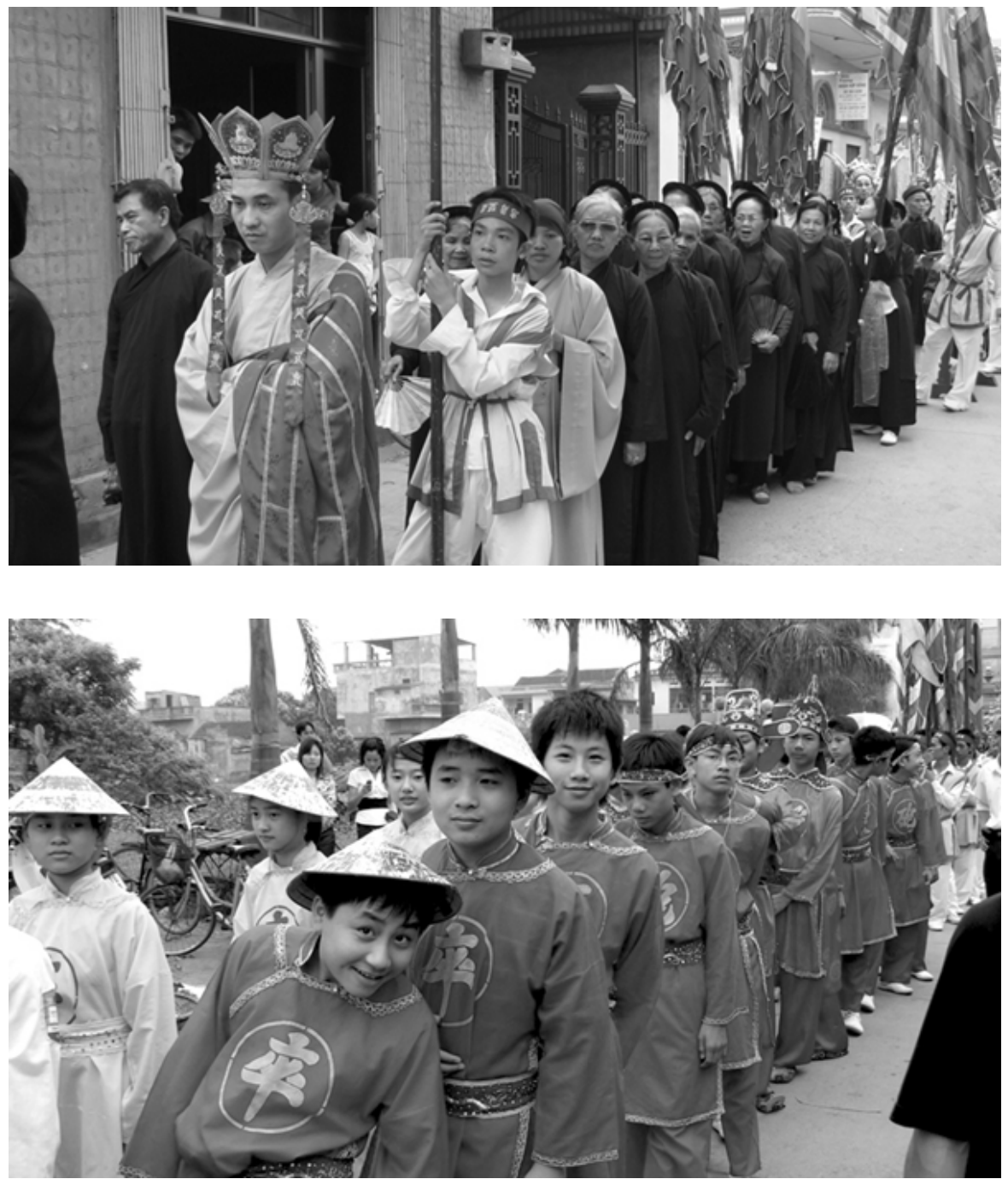
Cadernos de Clio, Curitiba, v. 11, $\mathrm{n}^{\circ} .2,2020$
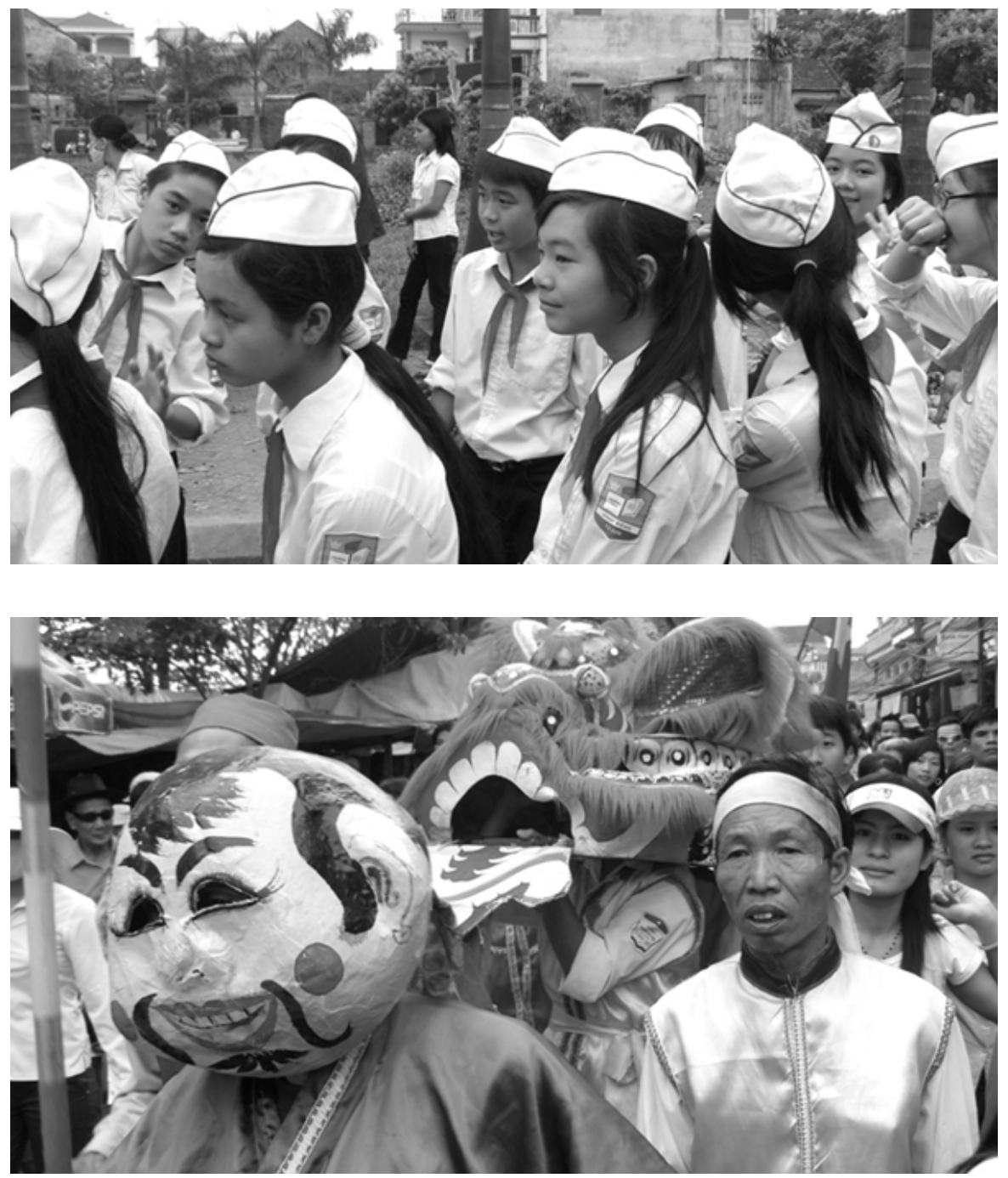
Cadernos de Clio, Curitiba, v. 11, nº . 2, 2020
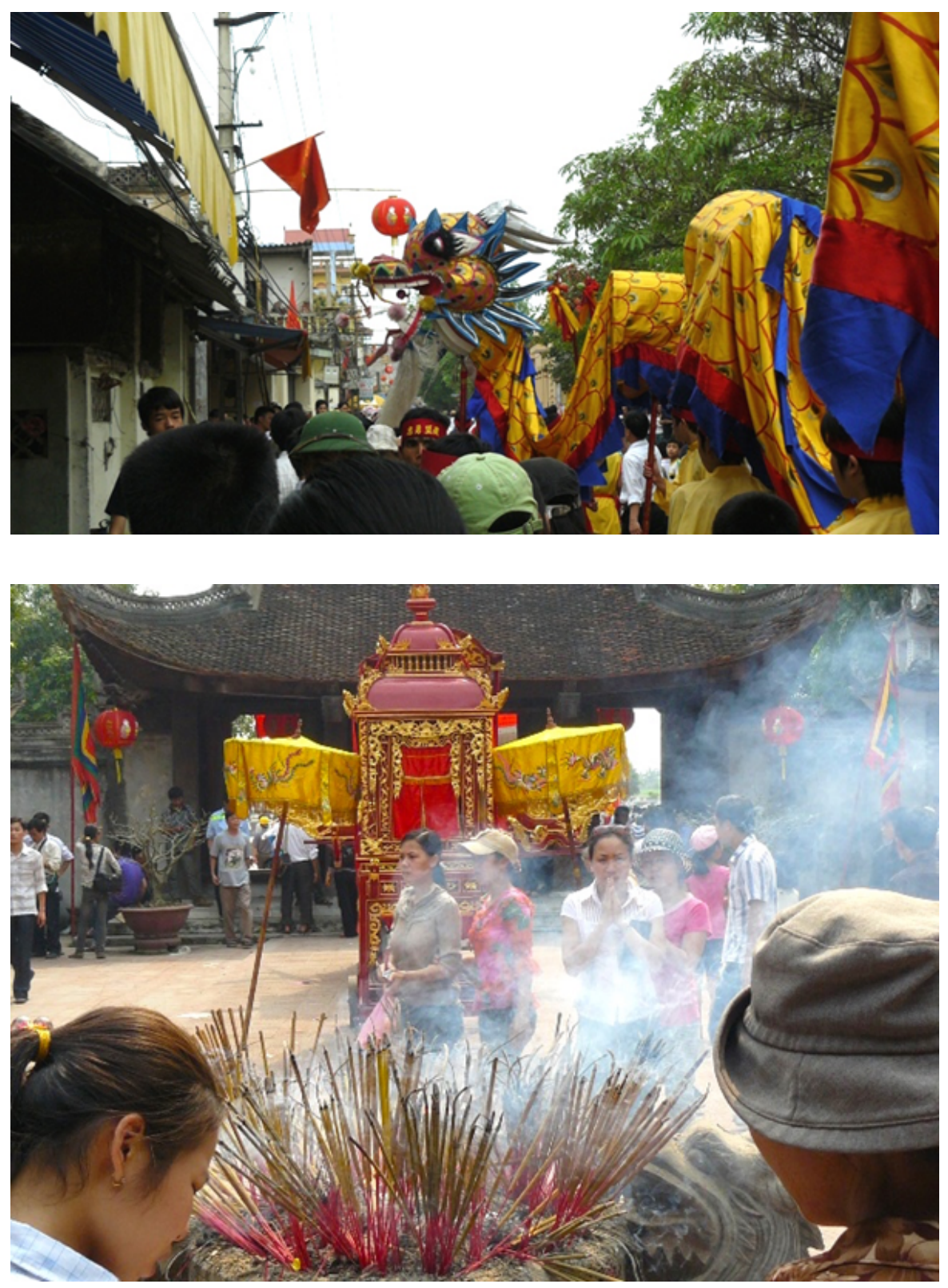
Cadernos de Clio, Curitiba, v. 11, $\mathrm{n}^{\circ} .2,2020$
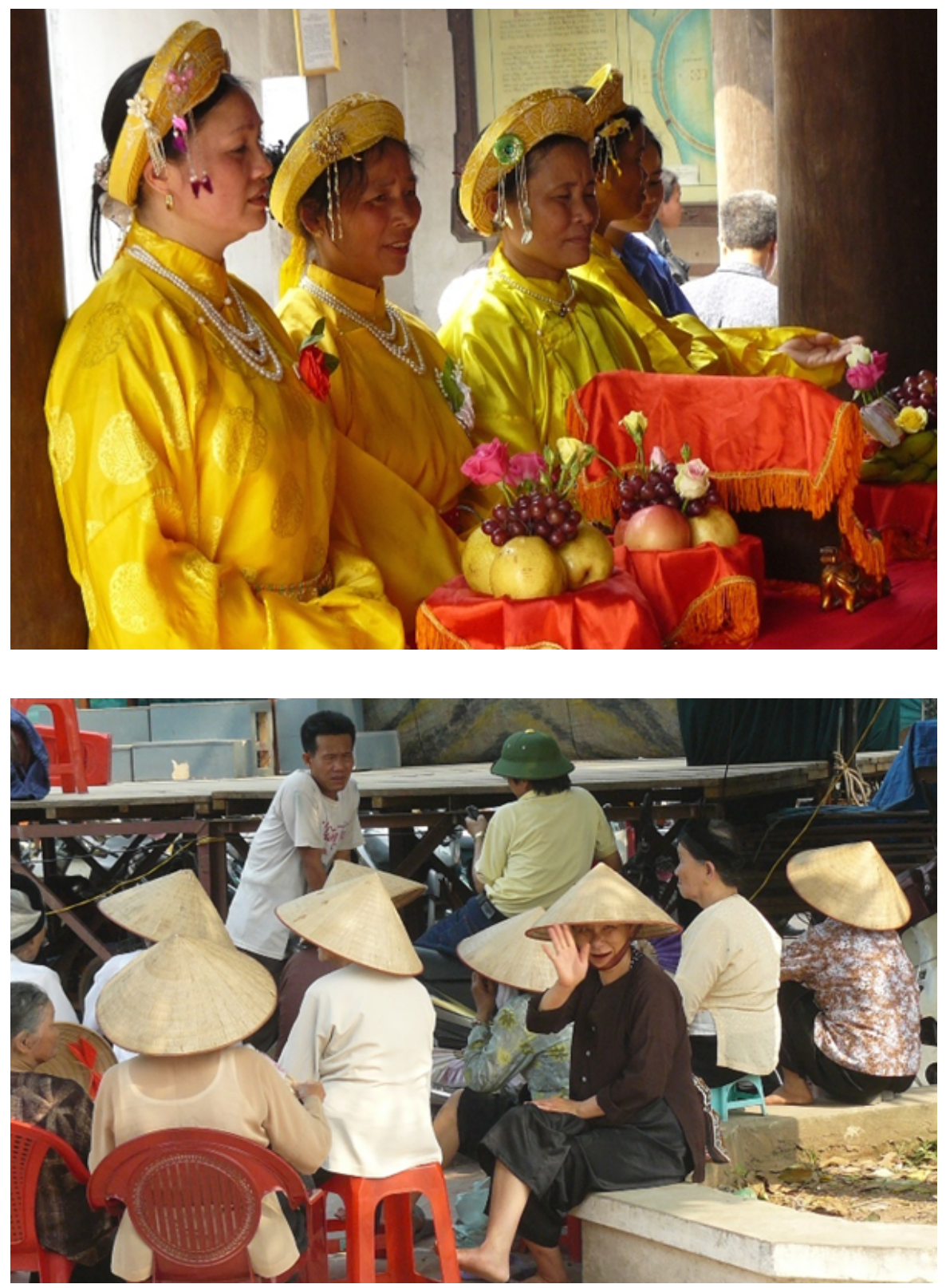


\section{Referências}

CHENG, Anne. La Chine pense-t-elle? Paris: Fayard, 2009.

DUIKER, William J. Historical Dictionary of Vietnam. $2^{\text {nd }}$ ed. In: Asian/Oceanian Historical Dictionaries. Boston: Scarecrow Press; Lanham; Md. \& London, 1998. n. 27.

DƯONG, Quảng Hàm. Leçons d'histoire d'Annam. Nam Dinh: Truong-Phat, 1927.

FANCHETTE, Sylvie; STEDMAN, Nicholas. À la découverte des villages de métier au Vietnam: Dix itinéraires autour de Hà Nội. Marseille: IRD Éditions, 2009.

GOSCHA, Christopher. Vietnam: A New History. New York: Basic Books, 2016.

KIERNAN, Ben. Việt Nam - A History from Earliest Times to the Present. New York: Oxford University Press, 2017.

LÊ, Thành Khôi. Le Viet-nam - Histoire et Civilization. Paris: Éditions de Minuit, 1955.

PAPIN, Philippe. Histoire de Hanoi. Paris: Fayard, 2001.

.Viêt-nam - Parcours d'une nation. Paris: La Documentation Française, 1999.

PHILLIPS, Douglas. Vietnam. Modern World Nations Coll. New York: Chelsea House, 2006.

TAYLOR, Keith Weller. A History of the Vietnamese. Cambridge: Cambridge University Press, 2013.

TRỊNH, Văn Thao. Vietnam du confucianisme au communisme. Paris: L'Harmattan, 1990. 
Cadernos de Clio, Curitiba, v. 11, $\mathrm{n}^{\circ} .2,2020$

VƯƠNG, Thu Trang; VƯONG, Quan Hoang. L'Indochine du XXIe-XXe siècle - politique et religions. Working Papers $C E B$, Université Libre de Bruxelles, n. 18-002, 2018.

Recebido em: 01/03/2021 Aceito em: 21/07/2021 